\title{
Electromagnetic Spider Web Placement in the Longmen Mountain Fault Zone
}

\author{
Min Jiang \\ Ningbo Polytechnic, Ningbo, China \\ Email: chiangm@163.com
}

How to cite this paper: Jiang, M. (2017) Electromagnetic Spider Web Placement in the Longmen Mountain Fault Zone. Open Access Library Journal, 4: e3463.

https://doi.org/10.4236/oalib.1103463

Received: February 17, 2017

Accepted: March 11, 2017

Published: March 14, 2017

Copyright $\odot 2017$ by author and Open Access Library Inc.

This work is licensed under the Creative Commons Attribution International License (CC BY 4.0).

http://creativecommons.org/licenses/by/4.0/

\begin{abstract}
The design of the electromagnetic spider web deployed in the Longmen Mountain fault zone, Sichuan province, is described. Instrument every year to replace the battery life can reach 20 years. In seismically active areas, the principle for deployment is placing multiple groups of wireless transmitting modules. These spider webs of multiple modules are capable of detecting about 30 square kilometers within the scope of magnetotelluric field changes. Each module is usually equipped with an electronic compass for detection of the magnetic anomaly; using a special timer it opens four times per minute for about 5 to $15 \mathrm{~s}$. If the signal is found to be abnormal, it can repeatedly scan many signals per hour. The signal is assessed by the GPRS network, which detects the seismic anomaly in the signal a few days before the earthquake as an early warning. Here, we focus on using ten tactics of ancient China as models for spatially deploying the electromagnetic spider web for further analysis of the quake epicenter. The equipment has low cost and low power consumption, so it is a good method for earthquake prediction.
\end{abstract}

\section{Subject Areas \\ Environmental Sciences}

\section{Keywords}

Earthquake Prediction, Longmen Mountain Fault Zone, Magnetic Switch Module, Wireless Transmitting and Receiving Module, GPRS Network Spider Nets, Electromagnetic Spider Web, Google Earth

\section{Introduction}

This paper describes the design of the electromagnetic spider web deployed in the Longmen Mountain fault zone, Sichuan province. A long-term spider electromagnetic field for one to two years was deployed in a seismically active area. 
The wireless transmitter modules are placed in three groups, $27 \mathrm{Mhz}, 40 \mathrm{Mhz}$, and $315 \mathrm{Mhz}$ by frequency, at distances of $30 \mathrm{~m}, 300 \mathrm{~m}$, and $3 \mathrm{~km}$ radius from the induction. This distribution can cover about $30 \mathrm{~km}^{2}$ within the scope of the Earth's magnetic field changes. Each module is usually equipped with an electronic compass for detection of the magnetic anomaly; using a special timer it opens four times per minute for about 5 to $15 \mathrm{~s}$ [1] [2] [3]. If the signal is found abnormal, it can repeatedly scan many signals per hour. A GSM remote alarm and remote software judge the magnetotelluric anomaly based on the signals. Using the multiple electromagnetic spider network remote monitoring, based on a GPRS network, an alarm can be produced a few days to a week before a strong earthquake. This is due to a change in the local electromagnetic field before the earthquake, which acts as an early warning. Ten different methods for spatial deployment, based on ancient warfare, provide a mechanism for further analysis of the earthquake epicenter. The equipment has been successfully manufactured at low cost, with low power consumption for outdoor installation equipment; in general, two $5 \#$ batteries can be used for one year. Therefore this method is good for short-term earthquake prediction [4] [5] [6].

\section{Longmen Mountain Fault Zone}

The Longmen Mountain fault zone is a thrust fault located in southwest China at the eastern margin of the Qinghai Tibet Plateau and intersects the Sichuan basin. (Figure 1) The Longmen Mountain main central fault is the main boundary fault for three fracture zones, about $500 \mathrm{~km}$ long, $70 \mathrm{~km}$ wide, and forms an earthquake prone area. Crustal movement produces pressure and tension;

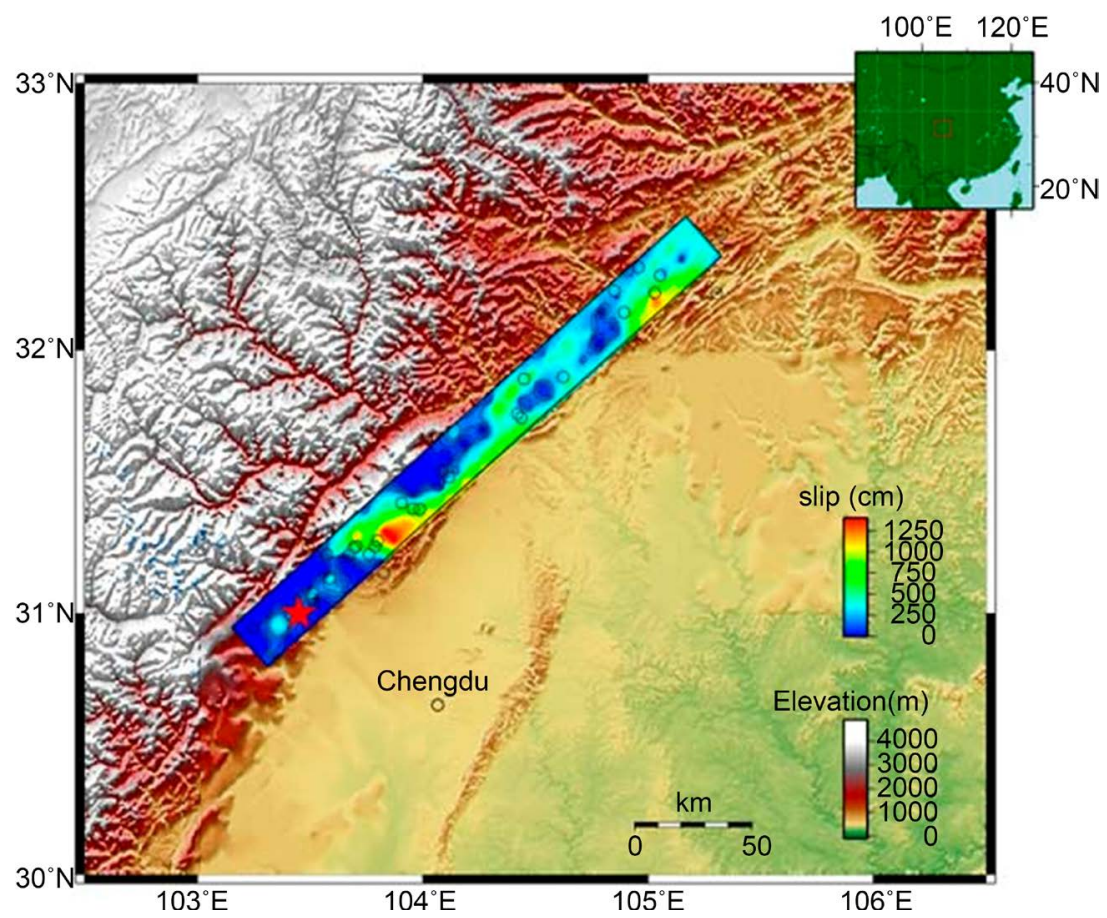

Figure 1. The Longmen Mountain fault zone, the location of the electromagnetic spider web deployment. 
pressure is common in convergent plates, such as the collision between the India Ocean plate, the front of the India continent, and the Eurasian plate. Tension is common in isolated plates, such as submarine expansion in the Red Sea rift or Great Rift Valley. Pressure and tension are complementary in crustal movement. For example, many faults are not separated from inland plate tension caused by the convergent plate, such oceanic plate subduction causing continental plate pressure, leading to uplift. However, this inevitably causes plate weakening and rifting. The aim of this study is to deploy an electromagnetic spider web that can capture the effects of such geophysical changes. After the Wenchuan earthquake occurred in 2008, many researchers began to monitor the geological activity in the Longmen Mountain fault zone. Our study is based in the Longmen Mountain area, and we use Google Earth to find suitable installation equipment locations for deployment [7] [8] [9].

\section{Google Earth}

Google Earth is a tool that makes it possible to investigate possible deployment locations in detail and is very practical because it reduces the need for manpower. Finding an abnormal electromagnetic point using usual methods is challenging because it is not easy to explore large, earthquake-prone, regions by foot. Employing Google Earth, it is easy to find geological anomalies. In order to reduce the cost of location deployment, we rely on Google Earth to determine the latitude and longitude of an appropriate site. Then we use a mobile phone to find the corresponding location on the map search. Latitude (E) and longitude $(\mathrm{N})$ are recorded in decimal degrees, which are easily transferred into binary code.

\section{Method Used to Determine Epicenter Location}

Figures 2-10 show different deployment patterns for the electromagnetic spider web relative to the epicenter detection location. These spatial distributions are based on ancient warfare methods.

Figure 2 shows the placement of the electromagnetic spider web as a single-line battle array. Electromagnetic spider nets are connected as groups in a straight line. The single-line battle array, a kind of war array, is based on the habits of snakes and deduction; soldiers are arranged in a line from head and tail a linear array, with two wings of cavalry for maneuvering ability. This is based on the saying that a hydra array is like a powerful python that can eat cattle. To get rid of a snake, the best way is to limit the wings of mobility.

Figure 3 shows the placement of the electromagnetic spider web as a two-dragon water outlet array. The electromagnetic spider nets are divided into two paths, which are connected into groups along a straight line. Electromagnetic spider webs are divided in two like two dragons, where the Dragon belongs to Yang, the water belongs to Yin. When the dragon is in the water everything is safe. After leaving water the two dragons are more powerful and unstoppable.

Figure 4 shows the placement of the electromagnetic spider web as Heaven and Earth powers array. The electromagnetic spider webs are divided into three 


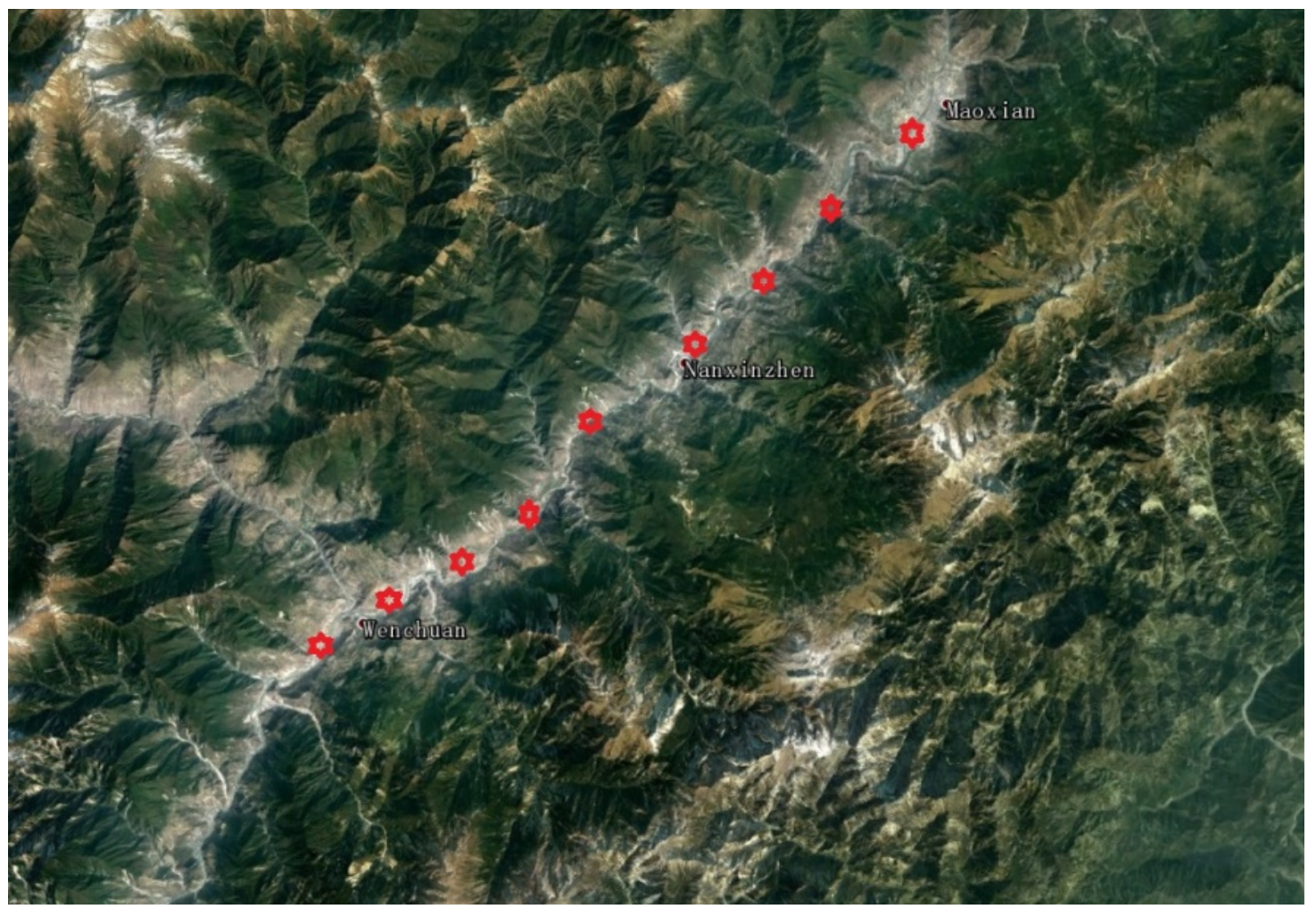

Figure 2. Single-Line battle arrays.

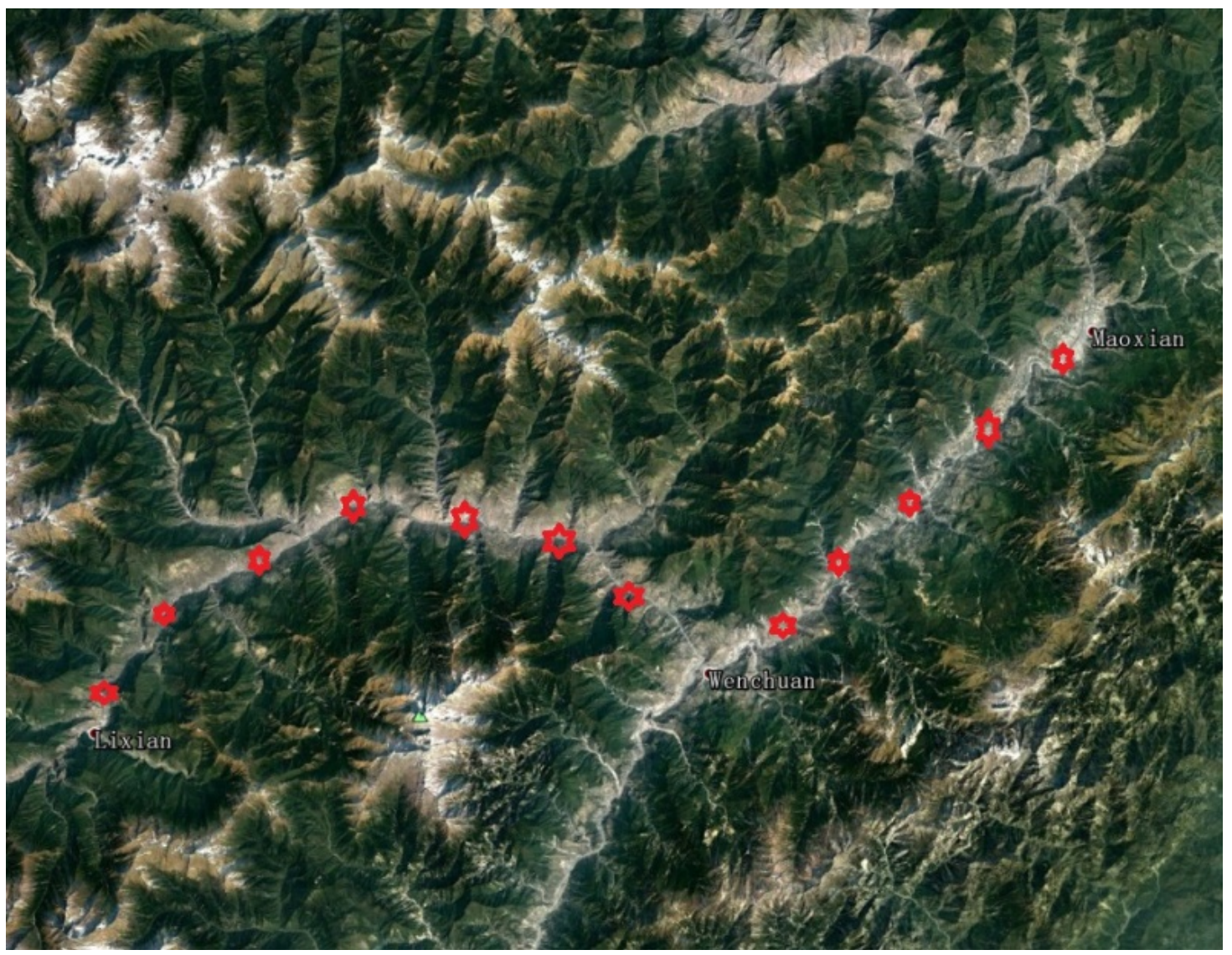

Figure 3. Two-Dragon water outlet arrays. 


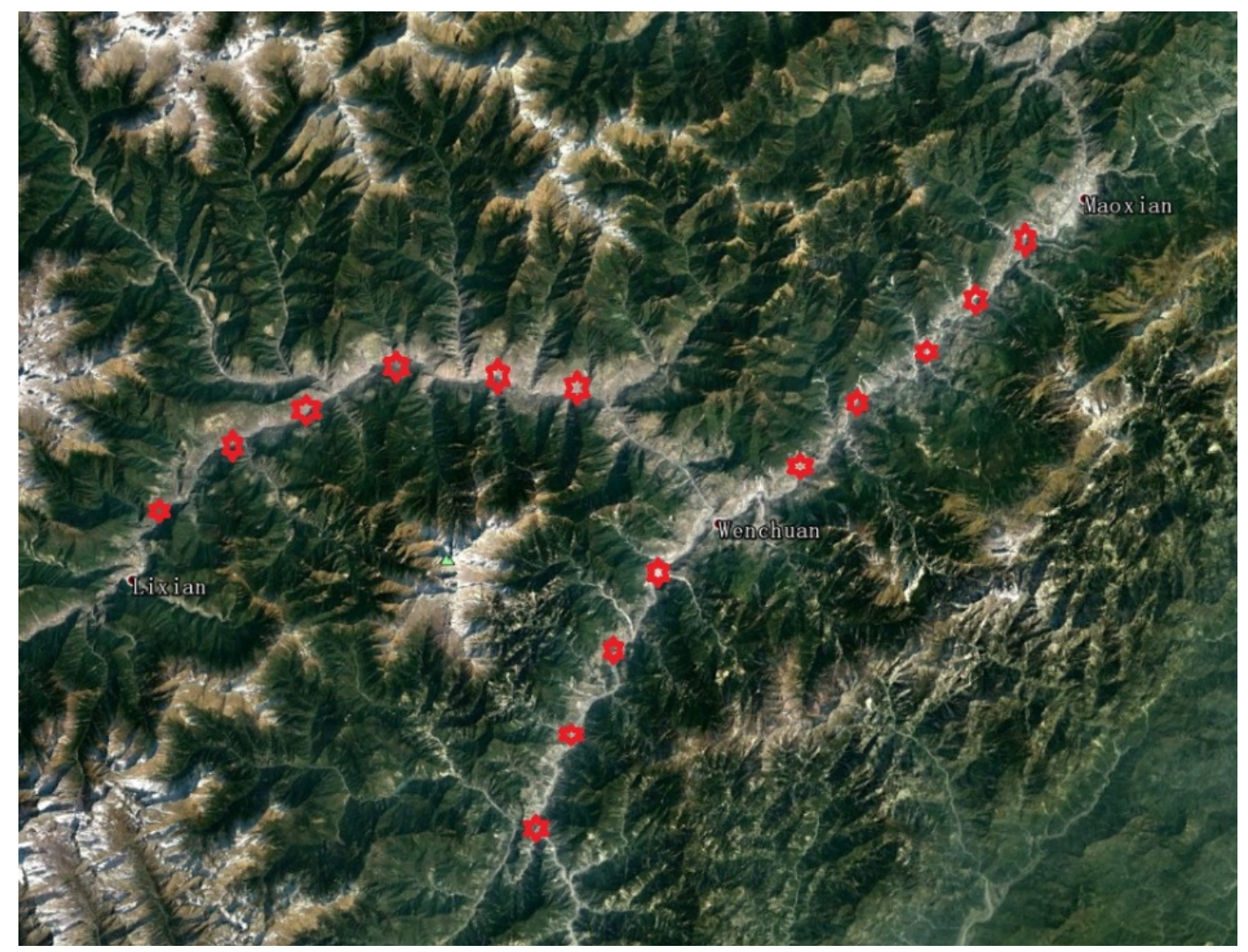

Figure 4. Heaven and Earth powers arrays.

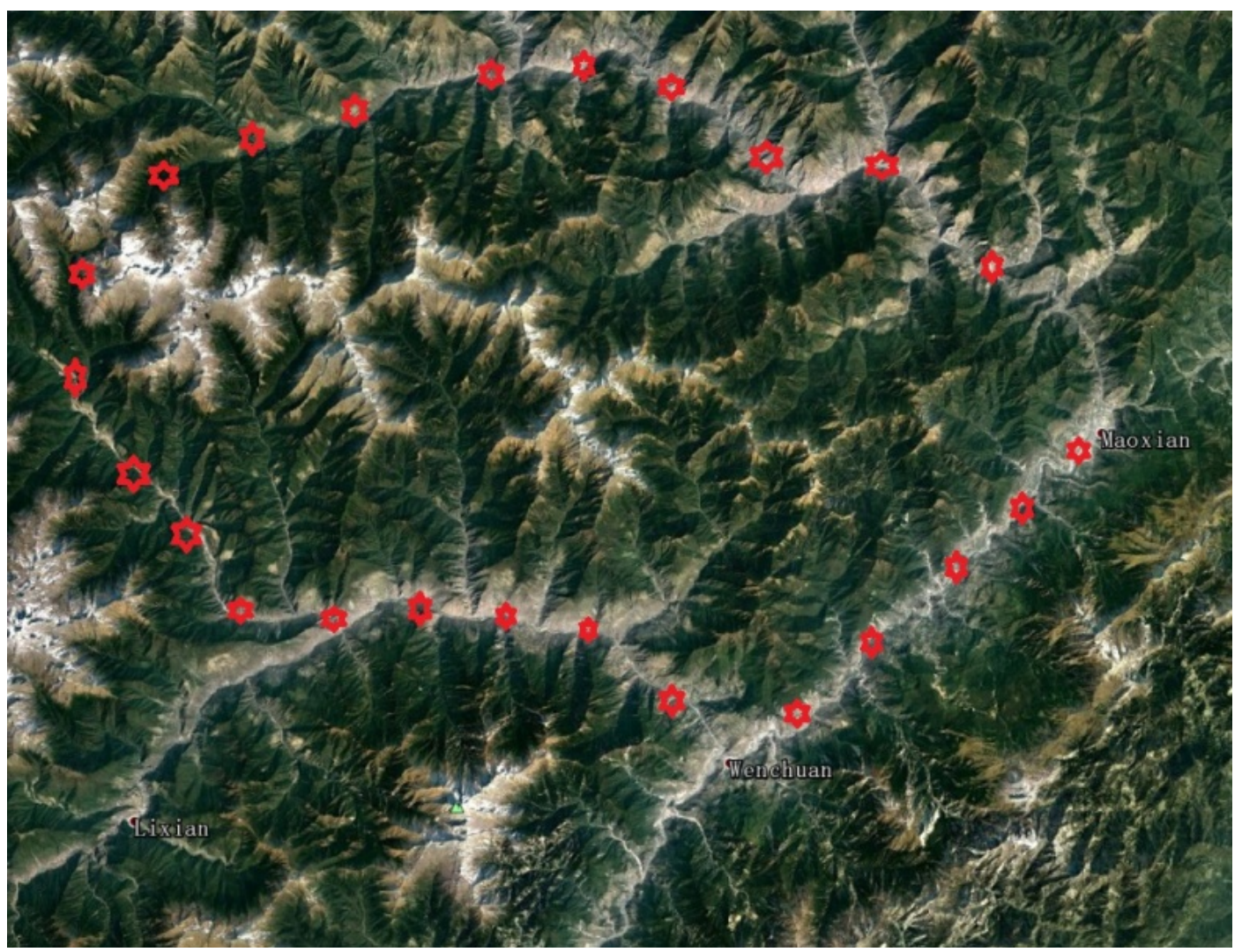

Figure 5. Four gate fallback arrays. 


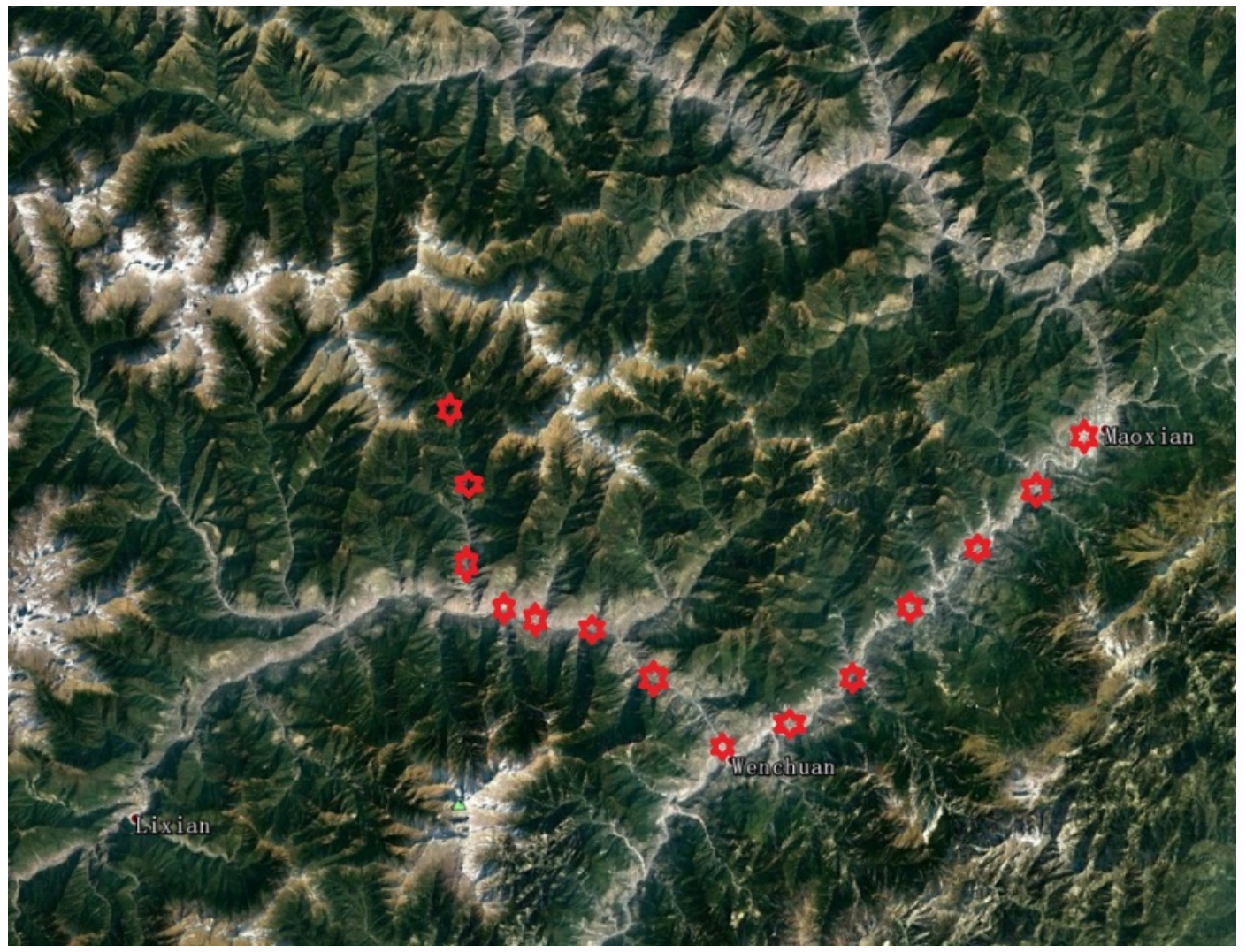

Figure 6. Five tigers and a large group of sheep arrays.

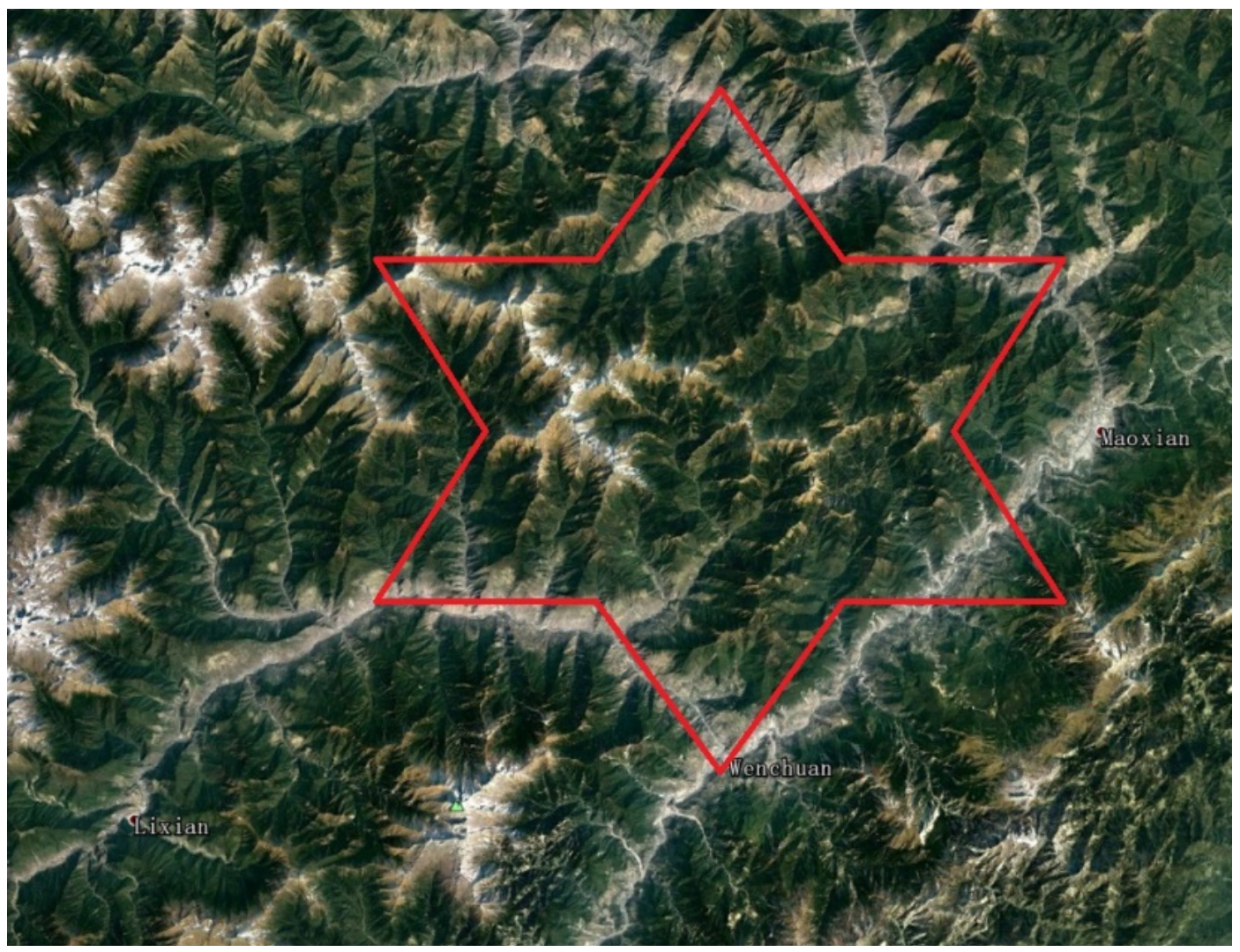

Figure 7. Six butyl arrays. 


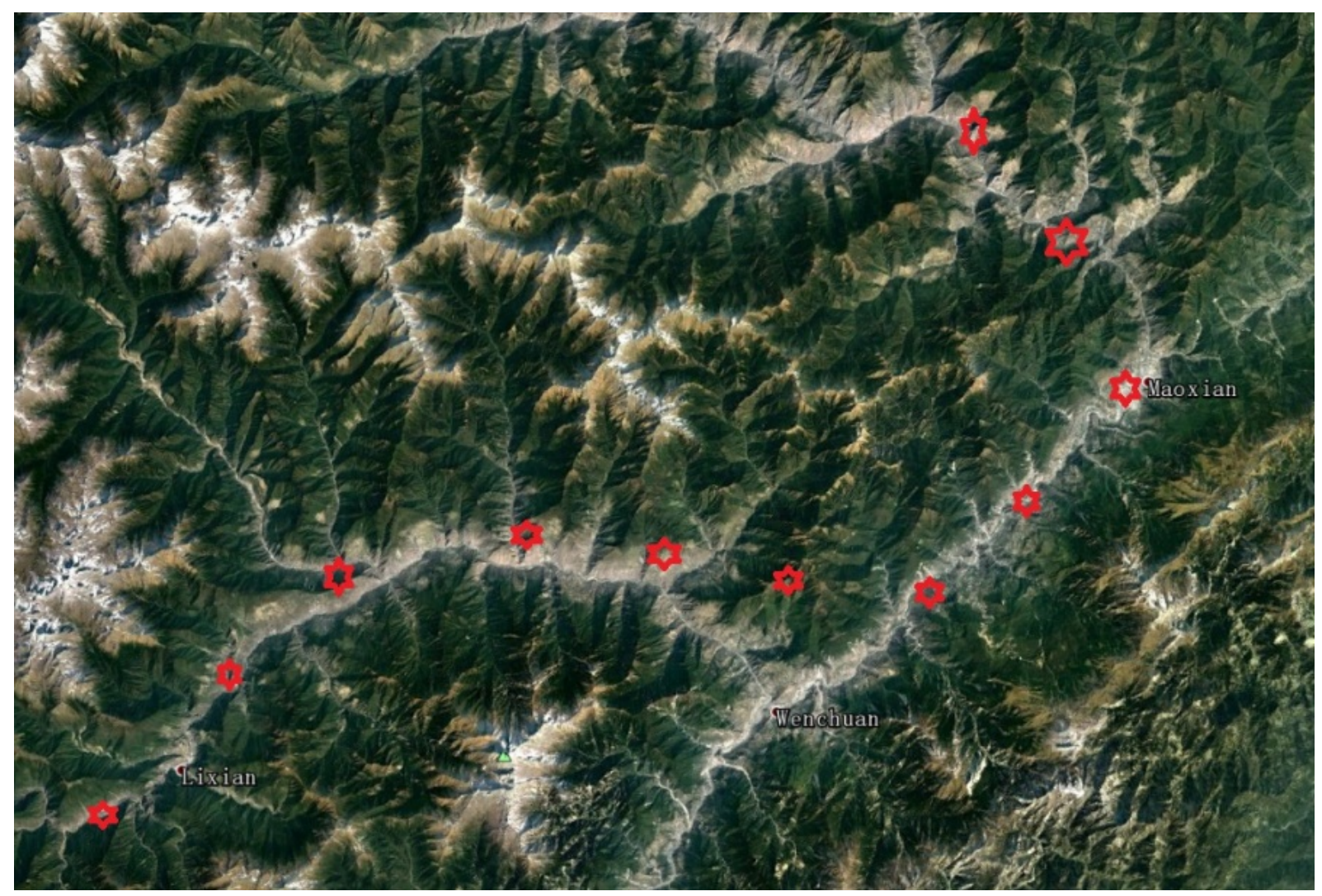

Figure 8. Big Dipper arrays.

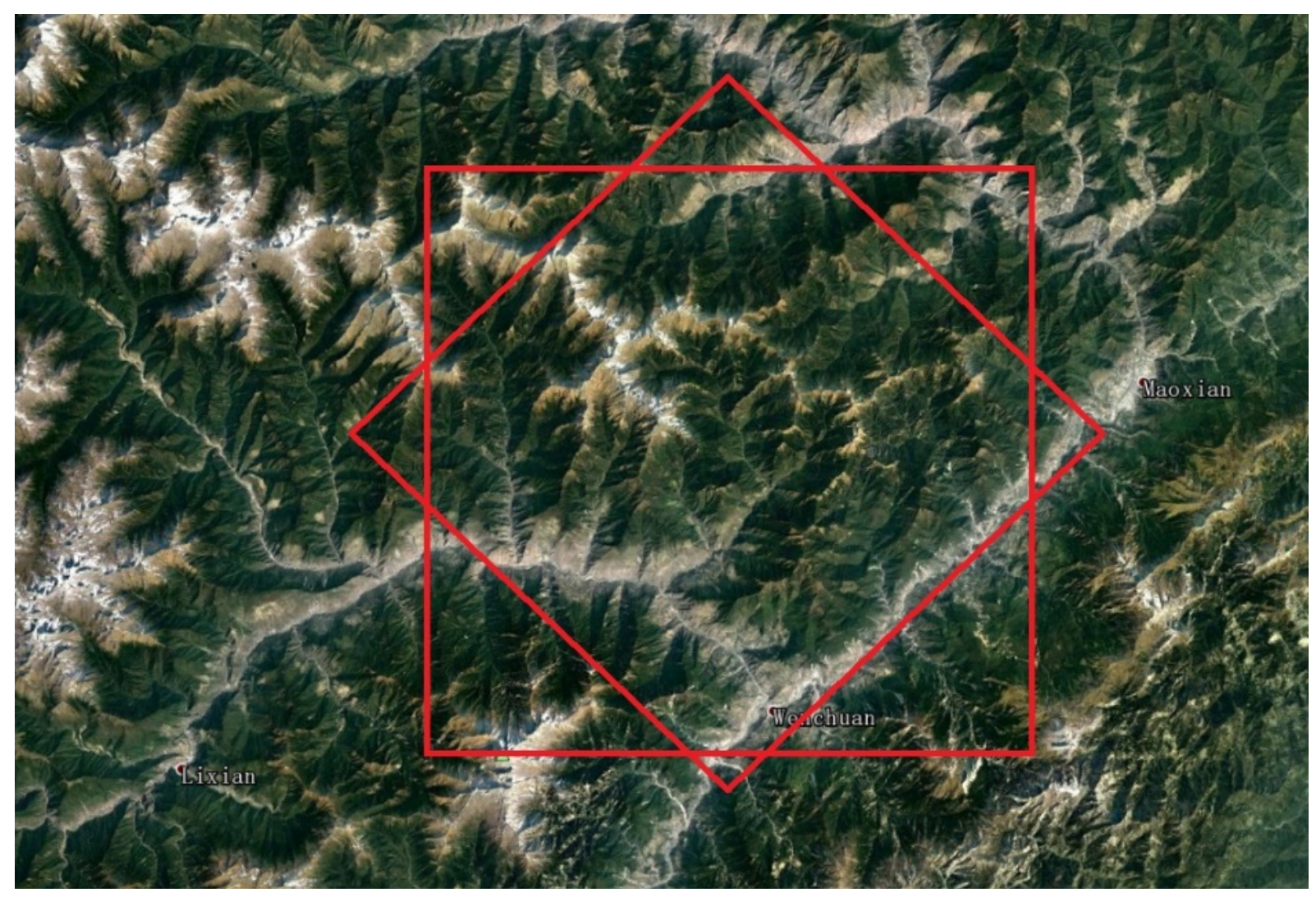

Figure 9. Eight golden arrays. 


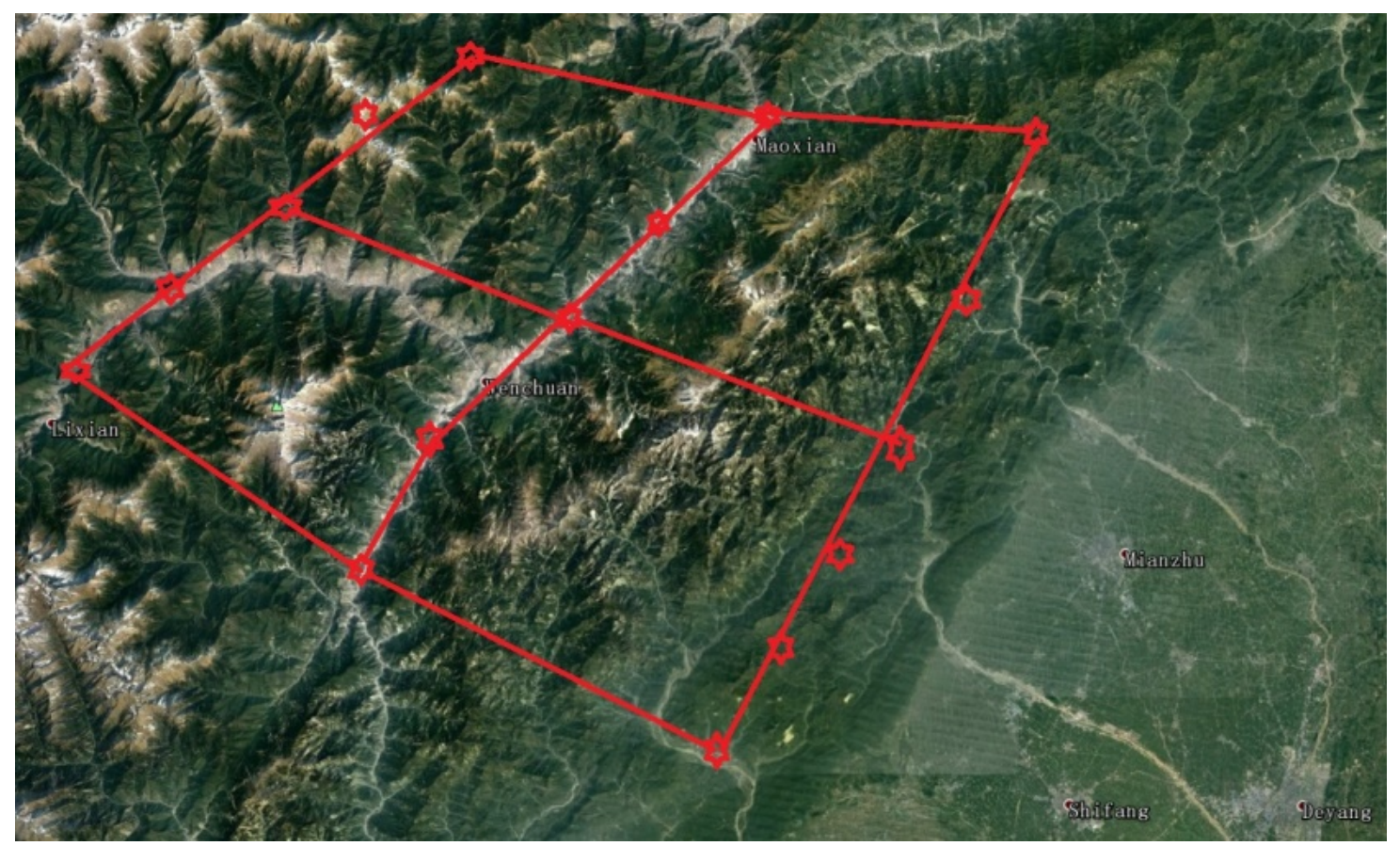

Figure 10. Nine character arrays.

groups; each group is connected in a straight line. Two opposing lines and one center perpendicular line form the Heaven and Earth powers array.

Figure 5 shows the placement of the electromagnetic spider web as a four gate fallback array. The electromagnetic spider network webs are divided into four groups of straight lines, connected into a rectangular group. The number of "four" is not publically popular in China because "four" is a homonym for "death" in Chinese. To Chinese people, "death" is taboo, and the expression "riding a crane" to "death" or "death" and "Xian" are expressions that cause shame. Generally, the Chinese people will not even have the number "four" in their mobile phone number. However, the four electromagnetic spider webs can be mutual reference such as four seasons in a year contain a life cycle: spring, summer, autumn and winter.

Figure 6 shows the placement of the electromagnetic spider web as five tigers and a large group of sheep. Multiple electromagnetic spider network soldiers are divided into five groups, and then lined up from beginning to end to form a V. The five tigers and a large group of sheep array is a method for combatting the main enemy on a psychological front. The equipment is deployed according to the $\mathrm{V}$ as a written word indicating the symbol for victory.

Figure 7 shows the placement of the electromagnetic spider web as six butyl arrays. Multiple electromagnetic spider network soldiers are divided into six Yang groups, six Yin groups, connected in a straight-line shape similar to the Israeli Star of David symbol. This spatial deployment symbolizes God and the six butyl Malacca God collectively. The God twelve were initially Tati's Ministry and the six butyl temple is based on sixty meridians in the temple of god. Yin and Yang together are a kind of mutual protection, equivalent to the protection of 
meaning. Butyl is the goddess. The six butyl is a legendary Taoist God Dharma. Malacca is God, and Tati men, "praying spirits", which could also be called "electromagnetic ghost".

Figure 8 shows the placement of the electromagnetic spider web as a Big Dipper array. Multiple electromagnetic spider network soldiers form seven points. From the beginning to the end of each with they form a straight-line shape into a Big Dipper group. The seven points of the Big Dipper are six electromagnetic cobwebs in two upside down and overlapping equilateral triangles. The specific length of electromagnetic spider web is a multiple of seven, and the central section is a larger electromagnetic spider web and a star, which is known as the seven arrays. It is said that the electromagnetic spider web placed into a star type has powerful energy. The seven star arrays can gather energy and will sense the limits of the magnetic field. Different types of star compositions in different types of the seven star arrays, such as a white seven star array can help protect the home from evil, scattered negative energy, and enhance spirituality and peace of mind.

Figure 9 shows the placement of the electromagnetic spider web as an eight golden array. The eight golden arrays is based on numerology. Eight is powerful in astrology, topography, and other factors for developing the ancient battlefield for war. Electromagnetic spider webs are divided into eight groups in a clockwise placement.

Figure 10 shows the placement of the electromagnetic spider web as a nine character array. The electromagnetic spider webs are divided into nine groups. The nine form a grid similar to a farmland line shape, thereby creating a nine character detector array.

Figure 11 shows the placement of the electromagnetic spider web as a ten

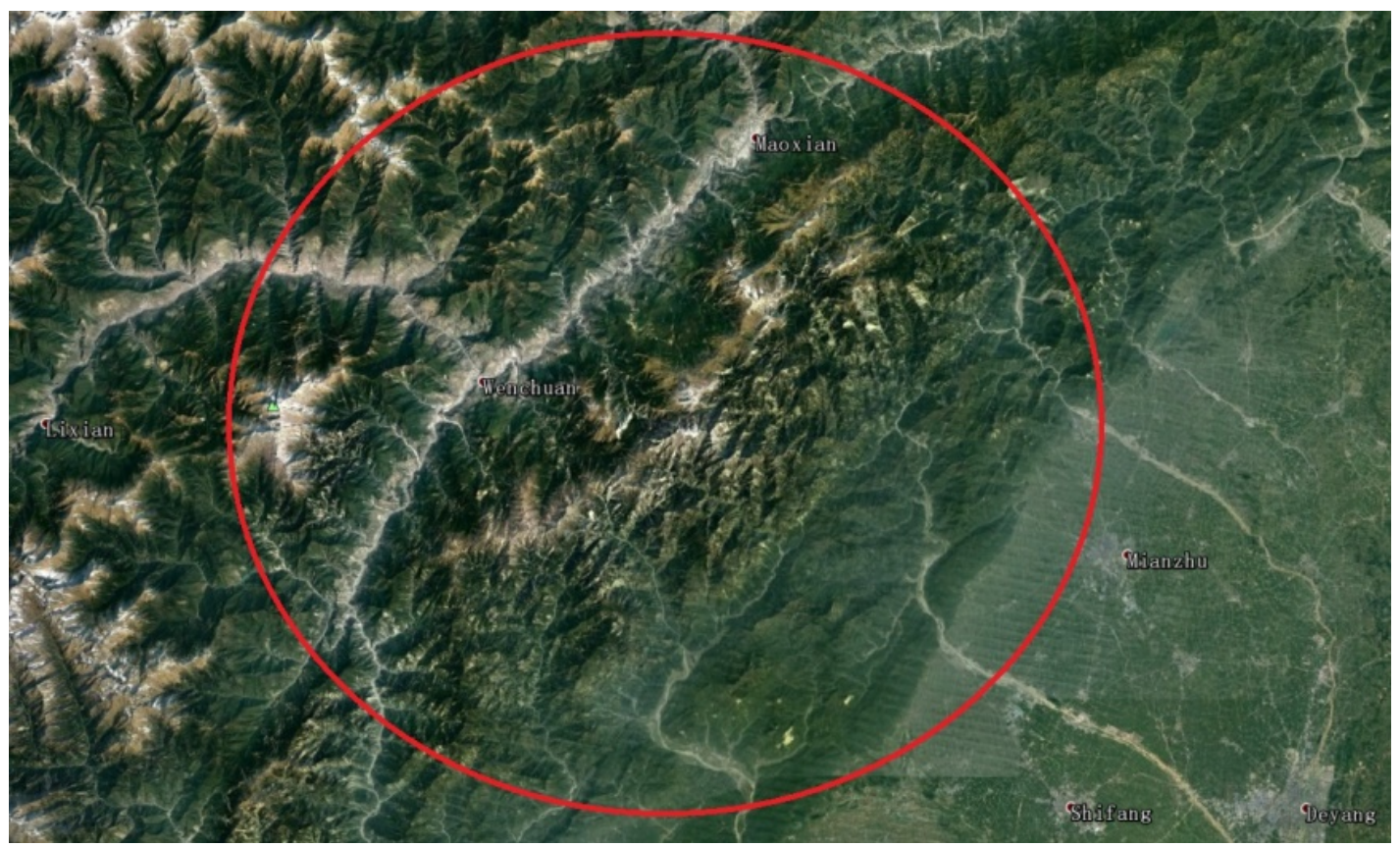

Figure 11. Ten piece ambush arrays. 
piece ambush array. This is one of the ten ancient arrays. The electromagnetic spider webs form ten groups joined end to end as a ten ambush array. This array acts as a lure for abnormal electromagnetic fields into the specified location. This array has no fixed pattern and is easily modified based on spatial necessity. This characteristic makes it ideal for an ambush in a mountain valley or other special terrain. The enemy, in this case the abnormal electromagnetic signal, is caught by the specified array ambush distribution. There is one of the most comprehensive and best methods to detect an earthquake center.

\section{Summary}

The Longmen Mountain fault zone is a thrust fault located in southwest China at the eastern margin of the Qinghai Tibet Plateau and intersects the Sichuan basin. The Longmen Mountain main central fault is the main boundary fault for three fracture zones, about $500 \mathrm{~km}$ long, $70 \mathrm{~km}$ wide, and forms an earthquake prone area.

Placing electromagnetic spider webs in the region around the Longmen Mountain fault is of practical significance to protect state property. This seismic belt is controlled by NE trending active faults controlled by the parallel coastline. In addition, some NW active faults also play a role in creating seismogenic conditions. Several destructive earthquakes have occurred along the fault zone. Deploying electromagnetic spider webs around the fault is of practical significance to protect state property. Unicom, mobile, coverage in the region can be easily used to obtain the electromagnetic information. Abnormal electromagnetic changes can be clearly and readily observed. When an instrument is installed, it will be connected with mobile data or Wi-Fi positioning. Once the phone is in $3 \mathrm{D}$ mode, clicking on the Google Earth GPS Icon will activate the network. Finding an earthquake epicenter location using ten ancient Chinese tactics, and the preceding electromagnetic anomalies is both relevant and significant [10] [11] [12] [13].

\section{References}

[1] Jiang, M. (1992) Multi Point Timing Control Circuit. Electric World Fourth, 4, 42.

[2] Jiang, M. (1996) Sound and Light Indicator of Electronic Compass. Electric World, 2,33 .

[3] Jiang, M. (2010) Earthquake Prediction Micro Integrated Measurement Recorder. Technology Innovation Herald, 29, 22-23.

[4] Jiang, M. (2013) How to Weave the Electromagnetic Spider Web to Predict Earthquakes. 2013 3rd International Conference on Education and Education Management (EEM 2013), 546-551.

[5] Jiang, M. (2014) Electromagnetic Spider Web Application in Earthquake Prediction. International Core Journal of Scientific Research \& Engineering Index, 111-114.

[6] Wang, X, et al. (2012) Deep Resistivity Structure along the Longmen Mountain Fault Zone in the Eastern Tibetan Plateau of China. AGU Fall Meeting Abstracts.

[7] Xu, X, et al. (2013) Integrated Study of Seismic and Gravity Data on the Crustal Structure across the Longmenshan Range, Eastern Tibetan Plateau. AGU Fall Meeting 
AGU Fall Meeting Abstracts.

[8] Zhao, G., Unsworth, M.J., Zhan, Y., et al. (2012) Crustal Structure and Rheology of the Longmenshan and Wenchuan Mw 7.9 Earthquake Epicentral Area from Magnetotelluric Data. Geology, 40, 1139-1142. https://doi.org/10.1130/G33703.1

[9] Jiang, M. (2014) The Group of Electromagnetic Spider Web, Economic, Business Management and Education Innovation (EBMEI 2014), 287-291.

[10] Jiang, M. (2014) Low Power Consumption Electromagnetic Spider Web. 2014 4th International Conference on Education and Education Management (EEM 2014), 74-78.

[11] Jiang, M. and Wang, P.Y. (2015) Simple Space Electric Field and Earth Magnetic Anomaly Remote Alarm System. 2015 International Conference on Frontiers of Manufacturing Science and Measuring Technology, 452-458.

[12] Jiang, M. (2016) Application of 3 Kinds of Practical Electromagnetic Spiders in Electromagnetic Spider Web. MATEC Web of Conferences.

[13] Jiang, M. (2016) Easily Magnetic Anomalies Earthquake Prediction. MMME 0509 10. https://doi.org/10.1051/matecconf/20166301020

Submit or recommend next manuscript to OALib Journal and we will provide best service for you:

- Publication frequency: Monthly

- 9 subject areas of science, technology and medicine

- Fair and rigorous peer-review system

- Fast publication process

- Article promotion in various social networking sites (LinkedIn, Facebook, Twitter, etc.)

- Maximum dissemination of your research work

Submit Your Paper Online: Click Here to Submit

Or Contact service@oalib.com 